\title{
Effects of Compatibility of Polymer Binders with Solvate Ionic Liquid Electrolytes on Discharge and Charge Reactions of Lithium-Sulfur Batteries
}

Toshitada Nakazawa, ${ }^{\mathrm{a}}$ Ai Ikoma, ${ }^{\mathrm{a}}$ Ryosuke Kido, ${ }^{\mathrm{a}}$ Kazuhide Ueno, ${ }^{\mathrm{a}, \mathrm{b}}$ Kaoru Dokko, ${ }^{\mathrm{a}}$

Masayoshi Watanabe $e^{\mathrm{a}, *}$

aDepartment of Chemistry and Biotechnology, Yokohama National University, 79-5 Tokiwadai,

Hodogaya-ku, Yokohama 240-8501, Japan

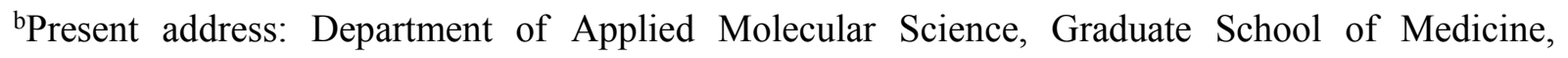
Yamaguchi University, 2-16-1 Tokiwadai, Ube, 755-8611, Japan

*CORRESPONDING AUTHOR: To whom correspondence should be addressed. Telephone/Fax:

+81-45-339-3955. E-mail: mwatanab@ynu.ac.jp 


\section{ABSTRACT}

Electrochemical reactions in Li-S cells with a solvate ionic liquid (SIL) electrolyte composed of tetraglyme (G4) and Li[TFSA] (TFSA: bis(trifluoromethanesulfonyl)amide) are studied. The sulfur cathode (S cathode) comprises sulfur, carbon powder, and a polymer binder. Poly(ethylene oxide) (PEO) and poly(vinyl alcohol) (PVA- $x)$ with different degrees of saponification $(x \%)$ are used as binders to prepare the composite cathodes. For the Li-S cell containing PEO binder, lithium polysulfides ( $\left.\mathrm{Li}_{2} \mathrm{~S}_{m}, 2 \leq m \leq 8\right)$, reaction intermediates of the $\mathrm{S}$ cathode, dissolve into the electrolyte, and $\mathrm{Li}_{2} \mathrm{~S}_{m}$ acts as a redox shuttle in the Li-S cell. In contrast, in the Li-S cell with PVA- $x$ binder, the dissolution of $\mathrm{Li}_{2} \mathrm{~S}_{m}$ is suppressed, leading to high columbic efficiencies during charge-discharge cycles. The compatibility of the PVA-x binder with the SIL electrolyte changes depending on the degree of saponification. Decreasing the degree of saponification leads in increased electrolyte uptake by the PVA- $x$ binder, increasing the charge and discharge capacities of Li-S cell. The rate capability of Li-S cell is also enhanced by the partial swelling of the PVA- $x$ binder. The enhanced performance of Li-S cell containing PVA- $x$ is attributed to the lowering of resistance of $\mathrm{Li}^{+}$ion transport in the composite cathode.

Keywords: Lithium batteries; Solvate ionic liquids; Tetraglyme; Polymer binder; Lithium polysulfide 


\section{INTRODUCTION}

Li-S batteries are attracting much attention as next generation energy storage devices $[1,2]$. The theoretical energy density of a Li-S battery is very high owing to the high theoretical capacities of a $\mathrm{Li}$ anode $\left(3860 \mathrm{mAhg}^{-1}\right)$ and an $\mathrm{S}$ cathode $\left(1672 \mathrm{mAhg}^{-1}\right)$. There have been numerous reports on $\mathrm{Li}$ anodes, nanostructured S cathodes, and electrolytes, and these have been summarized in recent review articles, for examples, see Refs. [3-12]. One issue that prevents the practical use of Li-S batteries is the dissolution of the $\mathrm{S}$ cathode into the liquid electrolytes during discharge and charge reactions $[13,14]$. The elemental sulfur $\left(\mathrm{S}_{8}\right)$ is electrochemically reduced to $\mathrm{Li}_{2} \mathrm{~S}$ at the cathode during discharge. Furthermore, lithium polysulfides $\left(\mathrm{Li}_{2} \mathrm{~S}_{m}, 2 \leq m \leq 8\right)$ are formed as intermediates of the cathode reactions, and $\mathrm{Li}_{2} \mathrm{~S}_{m}$, in particular, long $\mathrm{Li}_{2} \mathrm{~S}_{m}$ with $4 \leq m \leq 8$, dissolves into conventional liquid electrolytes [14]. The dissolution of the cathode active material causes significant problems such as rapid capacity fade and low coulombic efficiency for discharging and charging the Li-S battery. The dissolved $\mathrm{Li}_{2} \mathrm{~S}_{m}$ acts as a redox shuttle between the cathode and anode in the cell, and this shuttle effect causes the low coulombic efficiency during discharging and charging of the cell [14]. To solve this problem, additives for liquid electrolytes are used. These work by forming a passivation layer on the Li metal anode $[15,16]$. In addition, polymer electrolytes [17-20], inorganic solid electrolytes [21,22], and ionic liquid electrolytes [23-25] have also been proposed.

Recently, we reported that glyme-Li salt complexes can be used as thermally stable electrolytes for lithium batteries [26-32]. Glymes ( $\mathrm{Gn}, n$ in $\left.\mathrm{CH}_{3}-\mathrm{O}-\left(\mathrm{CH}_{2}-\mathrm{CH}_{2}-\mathrm{O}\right)_{n}-\mathrm{CH}_{3}\right)$ possess strong solvation power for $\mathrm{Li}^{+}$ions and form relatively long-lived (stable) solvates with $\mathrm{Li}^{+}$ions in certain molar ratios, $\left[\mathrm{Li}(\mathrm{glyme})_{x}\right]^{+}[33-38]$. Of particular interest, triglyme (G3) and tetraglyme (G4) form low melting complexes with Li[TFSA] (TFSA: bis(trifluoromethanesulfonyl)amide) in 1:1 molar 
ratio. The molten complexes are representative solvate ionic liquids (SILs) composed of solvate $\left[\mathrm{Li}(\mathrm{G} 3 \text { or G4) }]^{+} \text {cations and [TFSA] }\right]^{-}$anions [39-45]. As well as conventional ionic liquids, the SILs, [Li(G3)][TFSA] and [Li(G4)][TFSA], possess low volatility, non-flammability, ionic conductivity $\left(\sim 10^{-3} \mathrm{~S} \mathrm{~cm}^{-1}\right)$, and a wide electrochemical window. In addition, we reported that the solubility of $\mathrm{Li}_{2} \mathrm{~S}_{m}$ in $[\mathrm{Li}(\mathrm{G} 3$ or G4)][TFSA] is very low, and the redox shuttle effect in a Li-S cell can be effectively suppressed using SIL electrolytes [30,31]. This led to the highly efficient discharge/charge and long charge-discharge cycle life ( $>400$ cycle) of a Li-S cell [31].

In this study, we focus on the effects of the compatibility of polymer binders with SIL electrolytes on the electrochemical reactions of the S cathode. Typically, the S cathode is composed of S (active material), carbon powder (conductive agent), and a polymer binder, and the composite cathode has a porous structure [2-4]. Ion transport takes place in the pores during the electrochemical reaction of S. In the porous composite cathode, the binder interconnects the carbon particles to form the electron conduction network, and the surface of active material is partially covered with the binder. Therefore, the distribution of polymer binder in the cathode and the compatibility of the polymer with the electrolyte have a significant effect on the charge-discharge performance of Li-S cell. In this work, poly(ethylene oxide) (PEO) and poly(vinyl alcohol) (PVA) with different degrees of saponification were used as binders to fabricate the composite cathode. The interactions between electrolyte and polymer binders and the electrochemical reactions of S cathode were analyzed. We found that the electrochemical reaction mechanism, discharge capacity, and rate capability of S cathode change depending on the compatibility of polymer binder with the electrolyte.

\section{EXPERIMENTAL}




\subsection{Materials}

Highly purified G4 was supplied by Nippon Nyukazai and used as received. A battery-grade Li[TFSA] was provided by Solvay Japan as courtesy sample. [Li(G4)][TFSA] electrolyte was prepared by mixing Li[TFSA] and G4 in 1:1 molar ratio in an Ar-filled glove box. The ionic conductivity of $[\mathrm{Li}(\mathrm{G} 4)][\mathrm{TFSA}]$ is $1.6 \mathrm{mS} \mathrm{cm}^{-1}$ at $30{ }^{\circ} \mathrm{C}[26]$.

PEO, PVA, and poly(vinyl acetate) (PVAc) were used in this study. Hereafter, PVA is denoted as PVA- $x$ according to the degree of saponification $\left(x\right.$ mol \%). The molecular weight $\left(M_{\mathrm{w}}\right)$ or degree of polymerization (d.p.) of polymers are as follows: PEO (Alfa Aesar, $M_{\mathrm{w}}=1,000,000$ ), PEO (Aldrich, $M_{\mathrm{w}}=36,000$ ), PVA-100 (Tokyo Chemical Industry, $x=97-100$, d.p. $=$ ca. 1750), PVA-90 (Wako Pure Chemical Industries, $x=86-90$, d.p. $=3100-3900$ ), PVA-80 (Tokyo Chemical Industry, $x=$ 78-82, d.p. = ca. 2000), PVA-66 (JAPAN VAM \& POVAL, $x=66$, d.p. = 520), and PVAc (Alfa Aesar, $\left.M_{\mathrm{w}}=50,000\right)$.

Elemental sulfur $\left(\mathrm{S}_{8}\right)$ was purchased from Wako Pure Chemical Industries. Carbon powder (Ketjenblack, specific surface area of $1270 \mathrm{~m}^{2} \mathrm{~g}^{-1}$ ) was kindly supplied from Lion Corporation and used as received. Li metal was purchased from Honjo Metal Co. and used as received.

\subsection{Measurements}

The self-diffusion coefficients of $\mathrm{G} 4, \mathrm{Li}^{+}$, and [TFSA] ${ }^{-}$in the electrolyte were determined by pulsed-field-gradient (PFG) NMR measurements. The measurements were performed on a JEOLECX400 NMR spectrometer with a 9.4 T narrow bore superconducting magnet equipped with a PFG probe and current amplifier. Detailed measurement conditions are reported elsewhere [46].

The $\mathrm{S}$ composite cathode was composed of $\mathrm{S}_{8}$, carbon powder, and a polymer. $\mathrm{S}$ composite 
cathodes were prepared according to a previously reported method [24]. The mass ratio of S8, carbon, and polymer in the S composite cathode was 60:30:10. The composite cathode was pasted on an Al foil current collector. The thickness of the composite cathode on $\mathrm{Al}$ foil was ca. $10 \mu \mathrm{m}$, and the mass loading of active material $\left(\mathrm{S}_{8}\right)$ was $0.5 \mathrm{mg} \mathrm{cm}^{-2}$. The prepared composite sheet was cut into a circular shape (16 mm diameter). Coin cells (2032 type) were fabricated in an Ar-filled glovebox. The composite cathode sheet (16 mm diameter), porous glass separator (GA-55, Advantec), Li metal foil (16 mm diameter), and an electrolyte $(160 \mu \mathrm{L})$ were encapsulated in a coin cell. Galvanostatic charge-discharge measurements for Li-S cells were conducted using an automatic charge/discharge instrument (HJ1001SD8, Hokuto Denko) at $30{ }^{\circ} \mathrm{C}$. Li-S cell was prepared in a fully charged state, and the charge- discharge cycle is defined as follows: 1st discharge $\rightarrow$ 2nd charge $\rightarrow$ 2nd discharge $\rightarrow$ 3rd charge $\rightarrow$ 3rd discharge, and so on. The coulombic efficiency was defined as ( $N$ th discharge capacity $) /(N$ th charge capacity). The specific capacity of the cell was calculated based on the mass of $\mathrm{S}_{8}$, and the gravimetric current density of $1672 \mathrm{~mA} \mathrm{~g}^{-1}$ (1 C-rate) corresponds to a geometric current density of $0.8 \mathrm{~mA} \mathrm{~cm}^{-2}$.

\section{RESULTS AND DISCUSSION}

Fig. 1 shows charge and discharge curves of the Li-S cells with PVA-100 and PEO $\left(M_{\mathrm{w}}=1,000,000\right)$ binders. Both cells containing PVA-100 and PEO binders showed two plateaus at 2.3 and $2.0 \mathrm{~V}$ during discharge. In the voltage range of $2.4-2.0 \mathrm{~V}, \mathrm{~S}_{8}$ is electrochemically converted into $\mathrm{Li}_{2} \mathrm{~S}_{m}$ (typically $m=4$ ) through the formation of $\mathrm{Li}_{2} \mathrm{~S}_{8}$ [4]. The flat voltage plateau at $2.0 \mathrm{~V}$ is ascribed to the reduction of $\mathrm{Li}_{2} \mathrm{~S}_{4}$ into $\mathrm{Li}_{2} \mathrm{~S}$. During charging, the cell containing PVA-100 binder had a single plateau at $2.3 \mathrm{~V}$. This charging curves agrees well with our previous results using the 
[Li(G4)][TFSA] electrolyte [31]. In contrast, the cell containing PEO binder had two plateaus during charging, corresponding to the two plateaus in the discharge curves. The charge and discharge reaction mechanisms of the cells will be discussed later. The cell with PVA-100 binder exhibited an initial discharge capacity of $800 \mathrm{mAhg}^{-1}$, and the capacity slightly decreased to $700 \mathrm{mAhg}^{-1}$ in the subsequent charge-discharge cycles, as shown in Fig. 1c. The initial discharge capacity of the cell with PEO binder was $1100 \mathrm{~mA} \mathrm{hg}^{-1}$ and was much higher than that of the cell with PVA-100 binder, suggesting that the utilization of active material in the composite cathode was increased by using PEO binder. The capacity of cell with PEO decreased gradually as the number of charge-discharge cycles increased; in contrast, the cell with PVA-100 had stable charge and discharge capacities. Fig. 1d shows the coulombic efficiency of the cells. The coulombic efficiency of the cell containing PVA100 was ca. $99 \%$ and was slightly higher than that of the cell containing PEO (ca. 97\%). The discrepancy between the cells with PVA-100 and PEO binders correlates with the solvate stability of $[\mathrm{Li}(\mathrm{G} 4)]^{+}$in the composite cathode and will be discussed later.

The solubilities of PVA-100 and PEO in the [Li(G4)][TFSA] electrolyte were tested. As shown in Fig. 2a, PVA-100 is insoluble in the electrolyte because of the strong hydrogen bonds formed between hydroxyl groups of PVA-100 molecules. PVA-100 molecules aggregate due to the inter- and intra-molecular hydrogen bonds; therefore, dry PVA-100 is stiff and brittle. [Li(G4)][TFSA] cannot break the hydrogen bonds of PVA-100, so solvation does not occur, and PVA100 is stiff, even in the electrolyte. The insolubility of the binder is one of the reasons for the low discharge capacity of the cell with PVA-100. $\mathrm{Li}^{+}$ion transport cannot occur at the parts covered with PVA-100 within the porous composite cathode, and $\mathrm{Li}^{+}$ion cannot reach the active material covered by PVA-100, resulting in low utilization of the active material. In contrast, PEO can dissolve in 
[Li(G4)][TFSA] (Fig. 2b). It is well known that PEO can dissolve Li salts into the polymer matrix and can be used as a polymer electrolyte [47]. In addition, glymes are oligoethers and are compatible with PEO, resulting in complete compatibility of PEO with [Li(G4)][TFSA]. The swelling and dissolution of PEO binder in the electrolyte facilitate approach of the $\mathrm{Li}^{+}$ions to the surface of the active material in the composite cathode. Furthermore, PEO binder may improve the reaction kinetics of S composite cathode $[48,49]$. These lead to the high utilization of the active material for charge and discharge reactions over the short-term operation ( $<50$ charge-discharge cycles) of the Li-S cell.

Recently, we reported the physicochemical properties of polymer solutions of $\mathrm{PEO} /[\mathrm{Li}(\mathrm{G} 4)][\mathrm{TFSA}][46]$. In that case, the $M_{\mathrm{w}}$ of PEO was 36,000 , which is different from that of the binder used in the present composite cathode; however, we can discuss the interaction between PEO and $[\mathrm{Li}(\mathrm{G} 4)][\mathrm{TFSA}]$ based on these previous results. We found that some $\mathrm{Li}^{+}$ions are coordinated to PEO through ligand exchange between G4 and PEO in the PEO/[Li(G4)][TFSA] mixture [46]. Table 1 shows the self-diffusion coefficients of $\mathrm{Li}^{+}$ions $\left(D_{\mathrm{Li}}\right), \mathrm{G} 4\left(D_{\text {glyme }}\right)$, and $[\mathrm{TFSA}]^{-}$ (DTFSA) in the PEO/[Li(G4)][TFSA $]$ mixture at $60^{\circ} \mathrm{C}$. In the case of $[\mathrm{Li}(\mathrm{G} 4)][\mathrm{TFSA}]$ (without PEO), the diffusion coefficients of $\mathrm{G} 4$ and $\mathrm{Li}^{+}$were almost identical. This suggests that the $\mathrm{G} 4$ and $\mathrm{Li}^{+}$ diffuse together in $[\mathrm{Li}(\mathrm{G} 4)][\mathrm{TFSA}]$, and almost all G4 molecules are coordinated to $\mathrm{Li}^{+}$and free (uncoordinated) G4 molecules are present only at very low levels in [Li(G4)][TFSA] [43]. The selfdiffusion coefficients of $\mathrm{Li}^{+}$ions and $[\mathrm{TFSA}]^{-}$decreased on increasing the PEO content. However, the diffusion coefficient of G4 had a minimum at $10 \mathrm{wt} \% \mathrm{PEO}$, and this gradually increased on further addition of PEO. This suggests that the solvated structure of $[\mathrm{Li}(\mathrm{G} 4)]^{+}$was destabilized by the addition of PEO. As reported in our previous paper, $D_{\text {glyme }} / D_{\mathrm{Li}}$ is a good metric for the solvate stability of $[\mathrm{Li}(\mathrm{G} 4)]^{+}$in electrolytes $[43,44]$. As the stability of complex structure of $[\mathrm{Li}(\mathrm{G} 4)]^{+}$is increased in 
the electrolyte, $D_{\text {glyme}} / D_{\text {Li }}$ approaches unity. On increasing the PEO content in the $\mathrm{PEO} /[\mathrm{Li}(\mathrm{G} 4)][\mathrm{TFSA}]$ mixture, the $D_{\text {glyme}} / D_{\text {Li }}$ value became greater than unity. This result suggests that the stability of $[\mathrm{Li}(\mathrm{G} 4)]^{+}$decreased on introduction of PEO, and ligand exchange of $\mathrm{Li}^{+}$took place in the mixture of $\mathrm{PEO} /[\mathrm{Li}(\mathrm{G} 4)][\mathrm{TFSA}]$, generating uncoordinated G4, which then diffused faster than $\mathrm{Li}^{+}$in the mixture. Therefore, the polymer solution of $\mathrm{PEO} /[\mathrm{Li}(\mathrm{G} 4)][\mathrm{TFSA}]$ is no longer a solvate ionic liquid.

Because the formation of PEO- $\mathrm{Li}^{+}$complexes proceeds in the $\mathrm{Li}-\mathrm{S}$ cell with PEO binder, the liberation of free G4 within the S composite cathode should also occur. The liberated G4 molecules can participate in the solvation of $\mathrm{Li}_{2} \mathrm{~S}_{m}\left(\mathrm{Li}_{2} \mathrm{~S}_{m}+2 \mathrm{G} 4 \rightarrow[\mathrm{Li}(\mathrm{G} 4)]_{2} \mathrm{~S}_{m}\right.$ or $\left.2[\mathrm{Li}(\mathrm{G} 4)]^{+}+\mathrm{S}_{m}{ }^{2-}\right)[24,31,32]$. The solvated $\mathrm{Li}_{2} \mathrm{~S}_{m}$ dissolves in the electrolyte easily. The two plateaus observed for the charging curve of cell with PEO binder also indicate that the dissolved $\mathrm{Li}_{2} \mathrm{~S}_{m}$ is involved in the electrochemical reaction of S cathode [24,31]. The low voltage plateau was attributed to the electrooxidation of $\mathrm{Li}_{2} \mathrm{~S}$ to $\mathrm{Li}_{2} \mathrm{~S}_{4}$, and some $\mathrm{Li}_{2} \mathrm{~S}_{4}$ dissolves into the electrolyte. The disproportionation reaction of $\mathrm{Li}_{2} \mathrm{~S}_{4}$ in the electrolyte produces longer $\mathrm{Li}_{2} \mathrm{~S}_{m}(4 \leq m \leq 8)$ species. The higher plateau is due to the oxidation of dissolved $\mathrm{Li}_{2} \mathrm{~S}_{m}$ to $\mathrm{S}_{8}$, and $\mathrm{S}_{8}$ is deposited at the carbon surface. Furthermore, the dissolved $\mathrm{Li}_{2} \mathrm{~S}_{m}$ acts as a redox shuttle in the Li-S cell. Actually, the coulombic efficiency of discharge/charge of cell with PEO is slightly lower than that of one with PVA-100. This suggests that the shuttle mechanism took place in the cell with PEO binder. However, the shuttle effect in the cell with PEO binder is not severe compared to use of $1 \mathrm{M} \mathrm{Li}[\mathrm{TFSA}] / \mathrm{G} 4$ electrolyte containing excess uncoordinated G4 [24,31]. This is because the viscosity of electrolyte in the S composite cathode containing PEO binder increases due to the dissolution of PEO [46]. The diffusion of $\mathrm{Li}_{2} \mathrm{~S}_{m}$ in the cell is slower than that in $1 \mathrm{M}$ Li[TFSA]/G4 electrolyte. 
The shuttle mechanism was effectively suppressed in the cell with PVA-100 because of the reduced solubility of $\mathrm{Li}_{2} \mathrm{~S}_{m}$. The solubility of $\mathrm{Li}_{2} \mathrm{~S}_{m}$ in the $[\mathrm{Li}(\mathrm{G} 4)][\mathrm{TFSA}]$ electrolyte is very low and less than $65 \mathrm{mM}$ (atomic concentration of S) while that in an electrolyte containing excess $\mathrm{G} 4,1 \mathrm{M}$ Li[TFSA]/G4 (Li[TFSA] : G4 = 1:4), is as high as $6000 \mathrm{mM}$ [31]. The uncoordinated G4 molecules are rarely generated in the cell with [Li(G4)][TFSA] electrolyte and PVA-100 binder because of the negligible interaction between PVA-100 and [Li(G4)][TFSA] electrolyte. When the electrochemical reactions of $\mathrm{S}$ composite cathode and $\mathrm{Li}$ metal anode take place in the cell, the $\mathrm{Li}^{+}$exchange occurs between the solvate ionic liquid and active materials, and uncoordinated G4 molecules are generated at the interface. However, as we previously reported, the uncoordinated G4 receives immediately $\mathrm{Li}^{+}$ from the neighboring $[\mathrm{Li}(\mathrm{G} 4)]^{+}$complex cation and forms again a complex, and the life-time of uncoordinated G4 is very short $\left(\sim 10^{-4} \mathrm{~s}\right)$ in the [Li(G4)][TFSA] electrolyte [26]. Consequently, the 1:1 mixture of G4-Li[TFSA] still behaves as an ionic liquid even though the $\mathrm{Li}^{+}$exchange takes place between $[\mathrm{Li}(\mathrm{G} 4)]^{+}$and active materials. In the cell with $[\mathrm{Li}(\mathrm{G} 4)][\mathrm{TFSA}]$ electrolyte and PVA-100, $\mathrm{Li}_{2} \mathrm{~S}_{m}$ predominantly remains in the solid state because of the low solubility of $\mathrm{Li}_{2} \mathrm{~S}_{m}$ in the electrolyte. Solid $\mathrm{Li}_{2} \mathrm{~S}_{m}$ is converted to solid $\mathrm{S}_{8}$ at the composite cathode without dissolution of $\mathrm{Li}_{2} \mathrm{~S}_{m}$ during charging [24,31]. As a result, a single charging plateau was observed for the cell containing PVA-100. However, the detailed reaction mechanism of the solid state conversion from $\mathrm{Li}_{2} \mathrm{~S}_{m}$ to $\mathrm{S}_{8}$ is not clear and requires further study.

As shown above, PVA-100 is incompatible with [Li(G4)][TFSA]. The degree of saponification of PVA can be controlled, and PVA- $x$ 's $(x<100)$ with different degrees of saponification ( $x$ mol \%) are commercially available. As well known, PVA is synthesized by the hydrolysis (saponification) of PVAc. PVA- $x$ with $x<100$ contains vinyl acetate moieties within the 
polymer chain. On decreasing the degree of saponification, the fraction of acetate moieties increases. We tested the solubility of the homopolymer of PVAc in [Li(G4)][TFSA] and found that PVAc dissolves into the electrolyte (Fig. 3a). Therefore, the compatibility of PVA- $x$ with [Li(G4)][TFSA] electrolyte changes depending on the degree of saponification. As can be seen in Fig. 3b, PVA-66 is swollen with [Li(G4)][TFSA]. The electrolyte uptake of PVA- $x$ was estimated as follows. PVA- $x$ film was fabricated by a solution casting method, and the obtained dry polymer film was immersed in [Li(G4)][TFSA] at $50{ }^{\circ} \mathrm{C}$ for $48 \mathrm{~h}$. Then, the weight change of PVA- $x$ film before and after the swelling was evaluated. The weights of PVA-80 and PVA-66 films increased by 8 and 17\%, respectively, owing to electrolyte uptake. In contrast, PVA-100 was negligibly swollen with electrolyte. The electrolyte uptake of PVA- $x$ increased on decreasing the degree of saponification. Therefore, we concluded that the [Li(G4)][TFSA] electrolyte was incorporated into the acetate moiety of the PVA- $x$ polymer chain, and the PVA- $x$ film was partially swollen with the electrolyte.

To investigate the interaction between the vinyl acetate moiety of PVA- $x(x<100)$ and the electrolyte, mixtures of PVAc homopolymer and [Li(G4)][TFSA] electrolyte were prepared. The selfdiffusion coefficients of $\mathrm{G} 4, \mathrm{Li}^{+}$, and [TFSA $]^{-}$in the mixtures were measured using PFG-NMR (Table 2). The diffusion coefficients of $\mathrm{Li}^{+}$ions, $\mathrm{G} 4$, and $[\mathrm{TFSA}]^{-}$decreased on increasing the content of PVAc, and this is due to the increase in the viscosity of the polymer solution. As PVAc content increased, $D_{\text {glyme }} / D_{\text {Li }}$ increased slightly. However, the increase of $D_{\text {glyme }} / D_{\text {Li }}$ on addition of PVAc is much smaller than that of the PEO/[Li(G4)][TFSA] system (Table 1), suggesting that the interaction between PVAc and $[\mathrm{Li}(\mathrm{G} 4)]^{+}$is much weaker than that between PEO and $[\mathrm{Li}(\mathrm{G} 4)]^{+}$. The weaker interaction between PVAc and $[\mathrm{Li}(\mathrm{G} 4)]^{+}$results in a higher stability of $[\mathrm{Li}(\mathrm{G} 4)]^{+}$in the mixture, and the generation of uncoordinated G4 is suppressed. 
The partial swelling of PVA- $x$ binder $(x<100 \%)$ in [Li(G4)][TFSA] electrolyte may be beneficial to achieve high utilization of the active material in the S composite cathode. Lacey et al. reported the effect of partial swelling of binder of S composite cathode on the performance of Li-S cell [50]. They used a copolymer of vinylidene difluoride and hexafluoropropylene (PVDF-HFP) as a binder in the Li-S cells with a conventional electrolyte containing excess solvent. PVDF-HFP binder was partially swollen with the conventional electrolyte and was effective in enhancing the discharge capacity of S composite cathode. In the present study, using PVA- $x$ binders, the generation of uncoordinated G4 in the Li-S cell with [Li(G4)][TFSA] electrolyte can be suppressed because of the weak interaction between the electrolyte and PVA- $x$. This is effective in inhibiting the dissolution of $\mathrm{Li}_{2} \mathrm{~S}_{m}$ and the shuttle mechanism (vide supra). To demonstrate the benefits of partial swelling of the PVA- $x$ binder in the $[\mathrm{Li}(\mathrm{G} 4)][$ TFSA] electrolyte, we fabricated Li-S cells with PVA- $x$ binders with different degrees of saponification. However, PVA-66 in the composite cathode expanded and swelled, consequently, it peeled away from the $\mathrm{Al}$ foil current collector when the electrolyte was dropped on the electrode. This suggests that the binding ability of PVA-66 is not sufficient to maintain the electrode structure in the electrolyte, and the relatively low molecular weight of PVA-66 (d.p. = 520) is a likely reason for the low binding ability. Therefore, the composite cathode with PVA-66 binder was excluded from the battery test.

The initial discharge and charge curves of the cells are shown in Fig. 4. The coulombic efficiency of discharge/charge of each cell is greater than $98 \%$. On increasing the saponification degree, the discharge and charge capacities increased. The partial swelling of the binder in the electrolyte facilitated $\mathrm{Li}^{+}$ion transport in the composite cathode, and the utilization of active material increased. Similar to the behavior of the cell containing PVA-100, each cell with PVA- $x(x<100)$ 
binder has two discharging and one charging voltage plateau. The single plateau during charging indicates the solid state conversion of $\mathrm{Li}_{2} \mathrm{~S}_{m}$ to $\mathrm{S}_{8}$, (vide supra), and the dissolution of $\mathrm{Li}_{2} \mathrm{~S}_{m}$ was effectively inhibited in the cells containing PVA- $x$ binders. As we expected, the generation of uncoordinated G4 in the Li-S cell with $[\mathrm{Li}(\mathrm{G} 4)][$ TFSA] electrolyte was suppressed using PVA- $\chi$ binder, resulting in the low solubility of $\mathrm{Li}_{2} \mathrm{~S}_{m}$ and the inhibition of shuttle mechanism. The charge and discharge capacities of each cell gradually decreased on increasing cycle number. This degradation was attributed to the volume change of active material in the S composite cathode during charge and discharge reactions. During the discharge reaction of the $\mathrm{S}$ cathode, the volume of the active material increased by ca. $80 \%$ due to the complete conversion of $\mathrm{S}_{8} \rightarrow 8 \mathrm{Li}_{2} \mathrm{~S}$. On cycling, the repeated volume changes of the active material loosen the electrical contacts between carbon and the active material, isolating it. Consequently, the electrically isolated active material cannot participate in the charge/discharge reaction, and the capacity of the cell is decreased.

It should be noted that the capacity retention of the $\mathrm{S}$ composite cathode is improved as increasing the degree of saponification of PVA- $x$, although the initial discharge capacity of cell is decreased on increasing the degree of saponification (Fig. 4c). The capacity retention ratios, $\left(25^{\text {th }}\right.$ discharge capacity $) /\left(2^{\text {nd }}\right.$ discharge capacity $)$, of the cells with PVA-100, PVA-90, and PVA-80 were 90,87 , and $85 \%$, respectively. The capacity retention of the cell with PEO binder was also lower than that containing PVA-100 binder (Fig. 1c). These results suggest that the stiffness of polymer binder has an effect on the cycling stability of $\mathrm{S}$ composite cathode. The stiffness of PVA- $X$ in the $[\mathrm{Li}(\mathrm{G} 4)][$ TFSA] electrolyte decreased as the degree decreasing the degree of saponification, because of the increased swelling of PVA-x. PEO also swells and dissolves in the [Li(G4)][TFSA] electrolyte of the Li-S cell. The repetition of volume expansion and shrinkage of active material within the 
composite cathode causes the gradual collapse of the porous structure if the polymer does not maintain tight binding between carbon particles in the electrode. This causes an increase in resistance of the S composite cathode because the ionic and electronic conduction paths deteriorate during the prolonged charge-discharge cycles. The stiff polymer binders are helpful in maintaining the electronic conduction path and porous structure of a composite electrode; and this is especially important when the electrode contains an active material that experiences large volume changes during charge and discharge reactions. Furthermore, other examples demonstrate that the use of stiff polymer binders is an effective way to achieve long charge-discharge cycle life of batteries [51-58]. For instance, the charge-discharge cycle stability of Si anode in a Li-ion battery is influenced by polymer binder. The volume of $\mathrm{Si}$ is increased by $300 \%$ during full lithiation $(\mathrm{Si} \rightarrow \mathrm{Li} 4.4 \mathrm{Si}$ ), and the cycle life of $\mathrm{Si}$ anode can be improved using stiff polymer binders such as sodium carboxymethyl cellulose [56], polyimides [57], and poly(acrylic acid) [58]. This suggests that the preservation of the electronic conduction network and porous structure of the composite electrodes is important for the charge-discharge cycling stability of batteries. It is worth mentioning that retaining the porous structure of $\mathrm{S}$ composite cathode is also important for the Li-S cells with conventional electrolytes containing excess solvents, in which the dissolution of $\mathrm{Li}_{2} \mathrm{~S}_{m}$ and depositions of $\mathrm{Li}_{2} \mathrm{~S}$ and $\mathrm{S}_{8}$ take place repeatedly during charge and discharge within the composite cathode [59]. However, an active material covered with stiff polymer cannot react with $\mathrm{Li}^{+}$; therefore, the distribution of polymer binder within the composite electrode is also important to achieve both high capacity and long cycle life.

The compatibility of binder also affects the charge-discharge rate capability of Li-S cells. Fig. 5 shows the discharge capacities on the current density. On decreasing the degree of saponification of PVA- $X$, the cells showed higher discharge capacities, even at high current densities. 
The partial swelling of binder in the electrolyte enhances $\mathrm{Li}^{+}$ion conduction in the $\mathrm{S}$ composite cathode, leading to the higher rate capability of the cell.

\section{CONCLUSIONS}

The compatibilities of polymer binders with [Li(G4)][TFSA] electrolyte in Li-S cells were studied. PEO and PVA- $x$ were used as binders to fabricate S composite cathodes of a Li-S cell. PEO is soluble in the $[\mathrm{Li}(\mathrm{G} 4)][\mathrm{TFSA}]$ electrolyte and forms complexes with $\mathrm{Li}^{+}$. The formation of PEO$\mathrm{Li}^{+}$complexes in the electrolyte results in the liberation of free $\mathrm{G} 4$ molecules. The liberated G4 molecules participate in the solvation of $\mathrm{Li}_{2} \mathrm{~S}_{m}$, which is an intermediate in the $\mathrm{S}$ cathode reaction, in the Li-S cell, and $\mathrm{Li}_{2} \mathrm{~S}_{m}$ dissolves into the electrolyte. $\mathrm{Li}_{2} \mathrm{~S}_{m}$ act as a redox shuttle in the Li-S cell, and the shuttle effect lowers the discharge/charge coulombic efficiency.

The compatibility of PVA- $x$ with $[\mathrm{Li}(\mathrm{G} 4)][\mathrm{TFSA}]$ changes depending on the degree of saponification $(x)$. PVA-100 is insoluble in the electrolyte. However, on decreasing the degree of saponification, the electrolyte uptake of PVA- $x$ binder increases. This is because the acetate moiety in PVA- $x(x<100)$ is compatible with [Li(G4)][TFSA] electrolyte. The interaction between the acetate moieties of PVA- $x$ and $[\mathrm{Li}(\mathrm{G} 4)]^{+}$is relatively weak, and the generation of uncoordinated G4 is inhibited, causing low solubility of $\mathrm{Li}_{2} \mathrm{~S}_{m}$ and suppression of the redox shuttle effect in the Li-S cell. On decreasing the degree of saponification, the charge and discharge capacities of Li-S cell increased. The rate capability of Li-S cell was also enhanced by the partial swelling of PVA- $x$ binder with electrolyte. The enhanced performance of Li-S cell with PVA- $x(x<100)$ is attributed to the lowering of resistance of $\mathrm{Li}^{+}$ion transport in the $\mathrm{S}$ composite cathode. 


\section{Acknowledgements}

This study was supported in part by Specially Promoted Research for Innovative Next Generation

Batteries (SPRING) of the Advanced Low Carbon Technology Research and Development Program

(ALCA) of the Japan Science and Technology Agency (JST), and JSPS KAKENHI (No. 15H03874

and No. 15K13815) from the Japan Society for the Promotion of Science (JSPS). 


\section{References}

[1] P. G. Bruce, S. A. Freunberger, L. J. Hardwick, J. M. Tarascon, Nat. Mater. 11 (2012) 19-29.

[2] X. Ji, K. T. Lee, L. F. Nazar, Nat. Mater. 8 (2009) 500-506.

[3] S. Evers, L. F. Nazar, Acc. Chem. Res. 46 (2012) 1135-1143.

[4] L. F. Nazar, M. Cuisinier, Q. Pang, MRS Bull. 39 (2014) 436-442.

[5] A. Manthiram, Y. Fu, Y.-S. Su, Acc. Chem. Res. 46 (2012) 1125-1134.

[6] Y.-X. Yin, S. Xin, Y.-G. Guo, L.-J. Wan, Angew. Chem. Int. Ed. 52 (2013) 13186-13200.

[7] A. Rosenman, E. Markevich, G. Salitra, D. Aurbach, A. Garsuch, F. F. Chesneau, Adv. Energy Mater. 5 (2015) 1500212.

[8] Y. Yang, G. Zheng, Y. Cui, Chem. Soc. Rev. 42 (2013) 3018-3032.

[9] J. Scheers, S. Fantini, P. Johansson, J. Power Sources 255 (2014) 204-218.

[10] M. Barghamadi, A. S. Best, A. I. Bhatt, A. F. Hollenkamp, M. Musameh, R. J. Reesc, T. Rüthera, Energy Environ. Sci. 7 (2014) 3902-3920.

[11] S. Zhang, K. Ueno, K. Dokko, M. Watanabe, Adv. Energy Mater. 5 (2015) 1500117.

[12] R. Cao, W. Xu, D. Lv, J. Xiao, J.-G. Zhang, Adv. Energy Mater. 5 (2015) 1402273.

[13] R. D. Rauh, K. M. Abraham, G. F. Pearson, J. K. Surprenant, S. B. Brummer, J. Electrochem. Soc. 126 (1979) 523-527.

[14] Y. V. Mikhaylik, J. R. Akridge, J. Electrochem. Soc. 151 (2004) A1969-A1976.

[15] D. Aurbach, E. Pollak, R. Elazari, G. Salitra, C. S. Kelley, J. Affinito, J. Electrochem. Soc. 156 (2009) A694-A702.

[16] Z. Lin, Z. Liu, W. Fu, N. J. Dudney, C. Liang, Adv. Funct. Mater. 23 (2013) 1064-1069.

[17] S. S. Jeong, Y. T. Lim, Y. J. Choi, G. B. Cho, K. W. Kim, H. J. Ahn, K. K. Cho, J. Power Sources 174 (2007) 745-750.

[18] D. Marmorstein, T. H. Yu, K. A. Striebel, F. R. McLarnon, J. Hou, E. J. Cairns, J. Power Sources 89 (2000) 219-226.

[19] H.-S. Ryu, H.-J. Ahn, K.-W. Kim, J.-H. Ahn, J.-Y. Lee, J. Power Sources 153 (2006) 360-364.

[20] J. L. Wang, J. Yang, J. Y. Xie, N. X. Xu, Y. Li, Electrochem. Commun. 4 (2002) 499-502.

[21] A. Hayashi, T. Ohtomo, F. Mizuno, K. Tadanaga, M. Tatsumisago, Electrochem. Commun. 5 (2003) 701-705.

[22] T. Kobayashi, Y. Imade, D. Shishihara, K. Homma, N. Nagao, R. Watanabe, T. Yokoi, A. Yamada, R. Kanno, T. Tatsumi, J. Power Sources 182 (2008) 621-625.

[23] L. X. Yuan, J. K. Feng, X. P. Ai, Y. L. Cao, S. L. Chen, H. X. Yang, Electrochem. Commun. 8 (2006) 610-614. 
[24] J.-W. Park, K. Yamauchi, E. Takashima, N. Tachikawa, K. Ueno, K. Dokko, M. Watanabe, J. Phys. Chem. C 117 (2013) 4431-4440.

[25] J.-W. Park, K. Ueno, N. Tachikawa, K. Dokko, M. Watanabe, J. Phys. Chem. C 117 (2013) 20531-20541.

[26] K. Yoshida, M. Nakamura, Y. Kazue, N. Tachikawa, S. Tsuzuki, S. Seki, K. Dokko, M. Watanabe, J. Am. Chem. Soc. 133 (2011) 13121-13129.

[27] H. Moon, R. Tatara, T. Mandai, K. Ueno, K. Yoshida, N. Tachikawa, T. Yasuda, K. Dokko, M. Watanabe, J. Phys. Chem. C 118 (2014) 20246-20256.

[28] H. Moon, T. Mandai, R. Tatara, K. Ueno, A. Yamazaki, K. Yoshida, S. Seki, K. Dokko, M. Watanabe, J. Phys. Chem. C 119 (2015) 3957-3970.

[29] N. Tachikawa, K. Yamauchi, E. Takashima, J.-W. Park, K. Dokko, M.Watanabe, Chem. Commun. 47 (2011) 8157-8159.

[30] C. Zhang, A. Yamazaki, J. Murai, J. W. Park, T. Mandai, K. Ueno, K. Dokko, M. Watanabe, J. Phys. Chem. C 118 (2014) 17362-17373.

[31] K. Dokko, N. Tachikawa, K. Yamauchi, M. Tsuchiya, A. Yamazaki, E. Takashima, J. W. Park, K. Ueno, S. Seki, N. Serizawa, M. Watanabe, J. Electrochem. Soc. 160 (2013) A1304-A1310.

[32] K. Ueno, J.-W. Park, A. Yamazaki, T. Mandai, N. Tachikawa, K. Dokko, M. Watanabe, J. Phys. Chem. C 117 (2013) 20509-20516.

[33] D. Brouillette, D. E. Irish, N. J. Taylor, G. Perron, M. Odziemkowski, J. E. Desnoyers, Phys. Chem. Chem. Phys. 4 (2002) 6063-6071.

[34] W. A. Henderson, J. Phys. Chem. B 110 (2006) 13177-13183.

[35] W. A. Henderson, N. R. Brooks, W. W. Brennessel, V. G. Young, Chem. Mater. 15 (2003) 4679-4684.

[36] W. A. Henderson, N. R. Brooks, V. G. Young, Chem. Mater. 15 (2003) 4685-4690.

[37] W. A. Henderson, F. McKenna, M. A. Khan, N. R. Brooks, V. G. Young, R. Frech, Chem. Mater. 17 (2005) 2284-2289.

[38] D. M. Seo, P. D.Boyle, R. D. Sommer, J. S. Daubert, O. Borodin, W. A. Henderson, J. Phys. Chem. B 118 (2014) 13601-13608.

[39] T. M. Pappenfus, W. A. Henderson, B. B. Owens, K. R. Mann, W. H. Smyrl, J. Electrochem. Soc. 151 (2004) A209-A215.

[40] T. Tamura, K. Yoshida, T. Hachida, M. Tsuchiya, M. Nakamura, Y. Kazue, N. Tachikawa, K. Dokko, M. Watanabe, Chem. Lett. 39 (2010) 753-755.

[41] C. Zhang, K. Ueno, A. Yamazaki, K. Yoshida, H.Moon, T.Mandai, Y. Umebayashi, K. Dokko, M. Watanabe, J. Phys. Chem. B 118 (2014) 5144-5153. 
[42] T. Mandai, K. Yoshida, K. Ueno, K. Dokko, M. Watanabe, Phys. Chem. Chem. Phys. 16 (2014) 8761-8772.

[43] K. Ueno, R. Tatara, S. Tsuzuki, S. Saito, H. Doi, K. Yoshida, T. Mandai, M. Matsugami, Y. Umebayashi, K. Dokko, M. Watanabe, Phys. Chem. Chem. Phys. 17 (2015) 8248-8257.

[44] K. Ueno, K. Yoshida, M. Tsuchiya, N. Tachikawa, K. Dokko, M. Watanabe, J. Phys. Chem. B 116 (2012) 11323-11331.

[45] K. Shimizu, A. A. Freitas, R. Atkin, G. G. Warr, P. A. FitzGerald, H. Doi, S. Saito, K. Ueno, Y. Umebayashi, M. Watanabe, J. N. Canongia Lopes, Phys. Chem. Chem. Phys. 17 (2015) $22321-22335$.

[46] R. Kido, K. Ueno, K. Iwata, Y. Kitazawa, S. Imaizumi, T. Mandai, K. Dokko, M. Watanabe, Electrochim. Acta 175 (2015) 5-12.

[47] M. Armand, Solid State Ionics 9-10 (1983) 745-754.

[48] M. J. Lacey, F. Jeschull, K. Edström, D. Brandell, Chem Commun. 49 (2013) 8531-8533.

[49] M. J. Lacey, F. Jeschull, K. Edström, D. Brandell, J. Power Sources 264 (2014) 8-14.

[50] M. J. Lacey, F. Jeschull, K. Edström, D. Brandell, J. Phys. Chem. C 118 (2014) 25890-25898.

[51] F. Jeschull, M. J. Lacey, D. Brandell, Electrochim. Acta 175 (2015) 141-150.

[52] F. Jeschull, D. Brandell, K. Edström, M. J. Lacey, Chem. Commun. 51 (2015) 17100-17103.

[53] S. Komaba, N. Yabuuchi, T. Ozeki, Z -J. Han, K. Shimomura, H. Yui, Y. Katayama, T. Miura, J. Phys. Chem. C 116 (2012) 1380-1389.

[54] S. Komaba, Y. Matsuura, T. Ishikawa, N. Yabuuchi, W. Murata, S. Kuze, Electrochem. Commun. 21 (2012) 65-68.

[55] N. Yabuuchi, Y. Matsuura, T. Ishikawa, S. Kuze, J.-Y. Son, Y.-T. Cui, H. Oji, S. Komaba, ChemElectroChem 1 (2014) 580-589.

[56] J. Li, R. B. Lewis, J. R. Dahn, Electrochem. Solid-State Lett. 10 (2007) A17-A20.

[57] S. Uchida, M. Mihashi, M. Yamagata, M. Ishikawa, J. Power Sources 273 (2015) 118-122.

[58] Z.-J. Han, N. Yabuuchi, K. Shimomura, M. Murase, H. Yui, S. Komaba, Energy Environ. Sci. 5 (2012) 9014-9020.

[59] S. S. Zhang, J. Electrochem. Soc. 159 (2012) A1226-A1229. 


\section{Figure Captions:}

Fig. 1. Discharge and charge and curves for the Li-S cells with (a) PVA-100 binder and (b) PEO $\left(M_{\mathrm{w}}=1,000,000\right)$ binder. Dependences of (c) the discharge-charge capacities and (d) coulombic efficiency on cycle number. Charge and discharge measurements were carried out at a current density of $139 \mathrm{~mA} \mathrm{~g}^{-1}$ at $30{ }^{\circ} \mathrm{C}$.

Fig. 2. Photographs of (a) PVA-100/[Li(G4)][TFSA] and (b) PEO $\left(M_{\mathrm{w}}=1,000,000\right) /[\mathrm{Li}(\mathrm{G} 4)][\mathrm{TFSA}]$. Polymers were mixed with $[\mathrm{Li}(\mathrm{G} 4)][\mathrm{TFSA}]$ electrolyte and stirred for $24 \mathrm{~h}$ at $80^{\circ} \mathrm{C}$.

Fig. 3. Photographs of (a) PVAc/[Li(G4)][TFSA] and (b) PVA-66/[Li(G4)][TFSA]. Polymers were mixed with [Li(G4)][TFSA] electrolyte and stirred for $24 \mathrm{~h}$ at $80^{\circ} \mathrm{C}$.

Fig. 4. Discharge and charge and curves of Li-S cells with (a) PVA-90 binder and (b) PVA-80 binder. Dependences of (c) discharge-charge capacities and (d) coulombic efficiency on cycle number. Charge and discharge measurements were carried out at a current density of $139 \mathrm{~mA} \mathrm{~g}^{-1}$ at $30^{\circ} \mathrm{C}$.

Fig. 5. Dependence of discharge capacity of Li-S cells on current density at $30{ }^{\circ} \mathrm{C}$. The cells were charged up to $3.3 \mathrm{~V}$ at a current density of $139 \mathrm{~mA} \mathrm{~g}^{-1}$ prior to each discharge test. 
Table 1. The self-diffusion coefficients of $\mathrm{Li}^{+}$ions $\left(D_{\mathrm{Li}}\right), \mathrm{G} 4\left(D_{\text {glyme }}\right)$, [TFSA $]^{-}\left(D_{\mathrm{TFSA}}\right)$, and $D_{\text {glyme }} / D_{\mathrm{Li}}$ in PEO $\left(M_{\mathrm{w}}=36,000\right) /[\mathrm{Li}(\mathrm{G} 4)][\mathrm{TFSA}]$ mixtures at $60^{\circ} \mathrm{C}$. Data are obtained from Ref. [46].

\begin{tabular}{|c|c|c|c|c|}
\hline & $D_{\text {glyme }}$ & $D_{\mathrm{Li}}$ & $D_{\text {TFSA }}$ & \multirow[t]{2}{*}{$D_{\text {glyme }} / D_{\mathrm{Li}}$} \\
\hline & \multicolumn{3}{|c|}{$\left(10^{-7} \mathrm{~cm}^{2} \mathrm{~s}^{-1}\right)$} & \\
\hline PEO $0 \mathrm{wt} \%$ & 4.73 & 4.71 & 4.56 & 1.00 \\
\hline PEO $10 \mathrm{wt} \%$ & 3.37 & 2.75 & 3.19 & 1.23 \\
\hline PEO $20 \mathrm{wt} \%$ & 3.79 & 2.11 & 3.20 & 1.80 \\
\hline PEO $30 \mathrm{wt} \%$ & 4.08 & 1.47 & 2.98 & 2.78 \\
\hline
\end{tabular}


Table 2. Self-diffusion coefficients of $\mathrm{Li}^{+}$ions $\left(D_{\mathrm{Li}}\right), \mathrm{G} 4\left(D_{\mathrm{glyme}}\right),[\mathrm{TFSA}]^{-}\left(D_{\mathrm{TFSA}}\right)$, and $D_{\mathrm{glyme}} / D_{\mathrm{Li}}$ in PVAc/[Li(G4)][TFSA] mixtures at $60^{\circ} \mathrm{C}$.

\begin{tabular}{lllll}
\hline & $D_{\text {glyme }}$ & $D_{\mathrm{Li}}$ & $D_{\text {TFSA }}$ & $D_{\text {glyme }} / D_{\mathrm{Li}}$ \\
\cline { 2 - 4 } & $\left(10^{-7} \mathrm{~cm}^{2} \mathrm{~s}^{-1}\right)$ & & \\
\hline PVAc 10 wt $\%$ & 2.18 & 2.13 & 2.22 & 1.02 \\
PVAc 20 wt $\%$ & 1.06 & 1.01 & 1.10 & 1.04 \\
PVAc 30 wt $\%$ & 0.55 & 0.49 & 0.73 & 1.12 \\
\hline
\end{tabular}



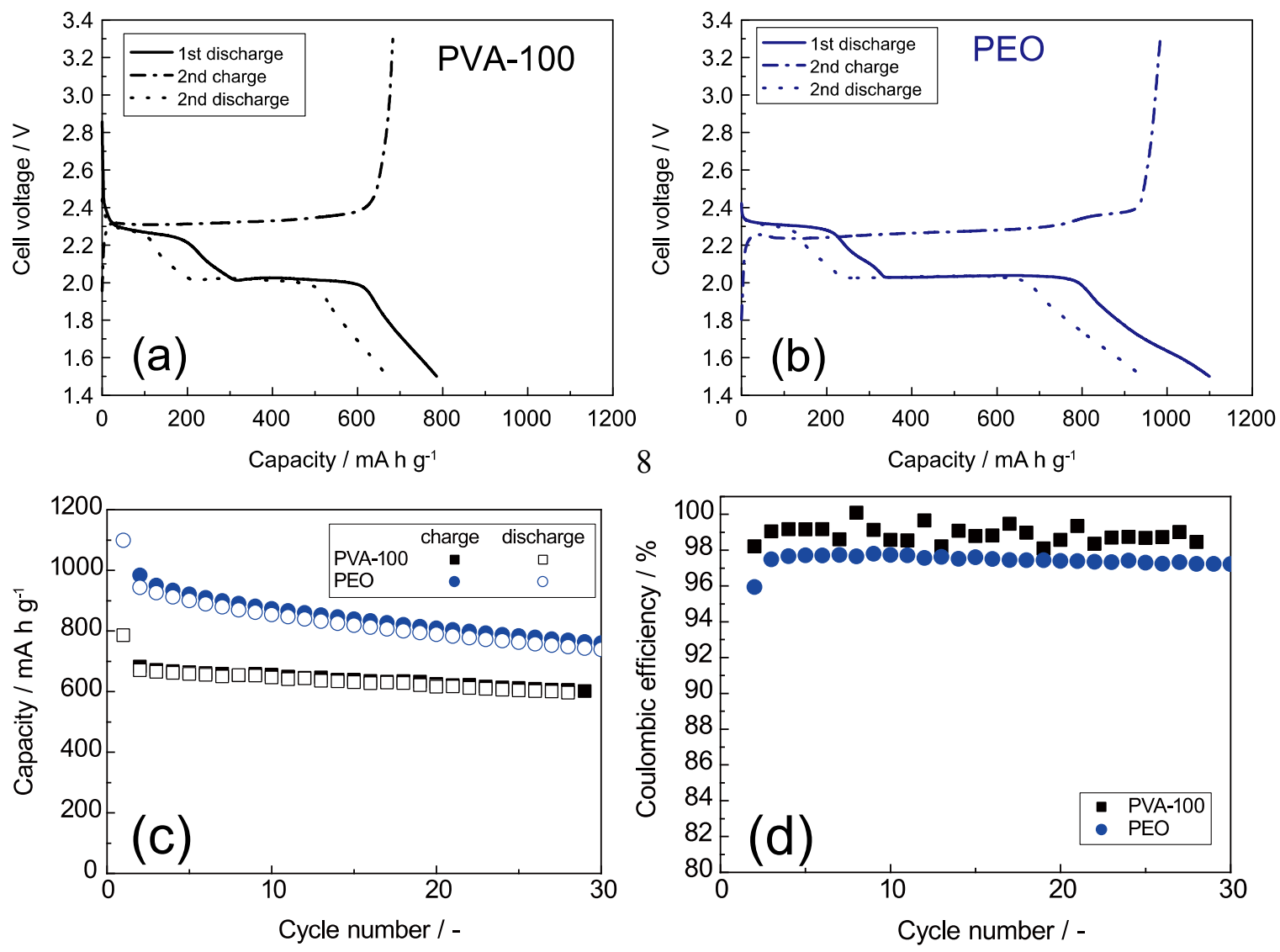

Fig. 1. Discharge and charge and curves for the Li-S cells with (a) PVA-100 binder and (b) PEO $\left(M_{\mathrm{w}}=1,000,000\right)$ binder. Dependences of (c) the discharge-charge capacities and (d) coulombic efficiency on cycle number. Charge and discharge measurements were carried out at a current density of $139 \mathrm{~mA} \mathrm{~g}^{-1}$ at $30{ }^{\circ} \mathrm{C}$. 

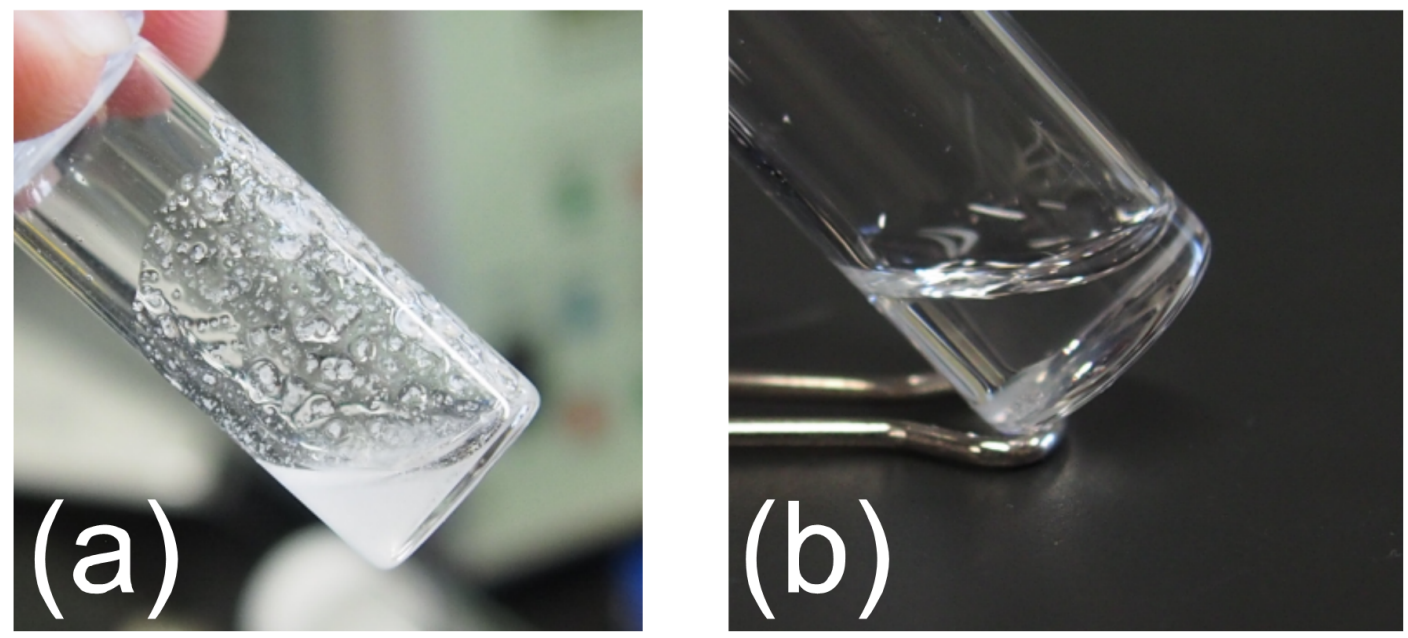

Fig. 2. Photographs of (a) PVA-100/[Li(G4)][TFSA] and (b) PEO $\left(M_{\mathrm{w}}=1,000,000\right) /[\mathrm{Li}(\mathrm{G} 4)][\mathrm{TFSA}]$. Polymers were mixed with [Li(G4)][TFSA] electrolyte and stirred for $24 \mathrm{~h}$ at $80^{\circ} \mathrm{C}$. 

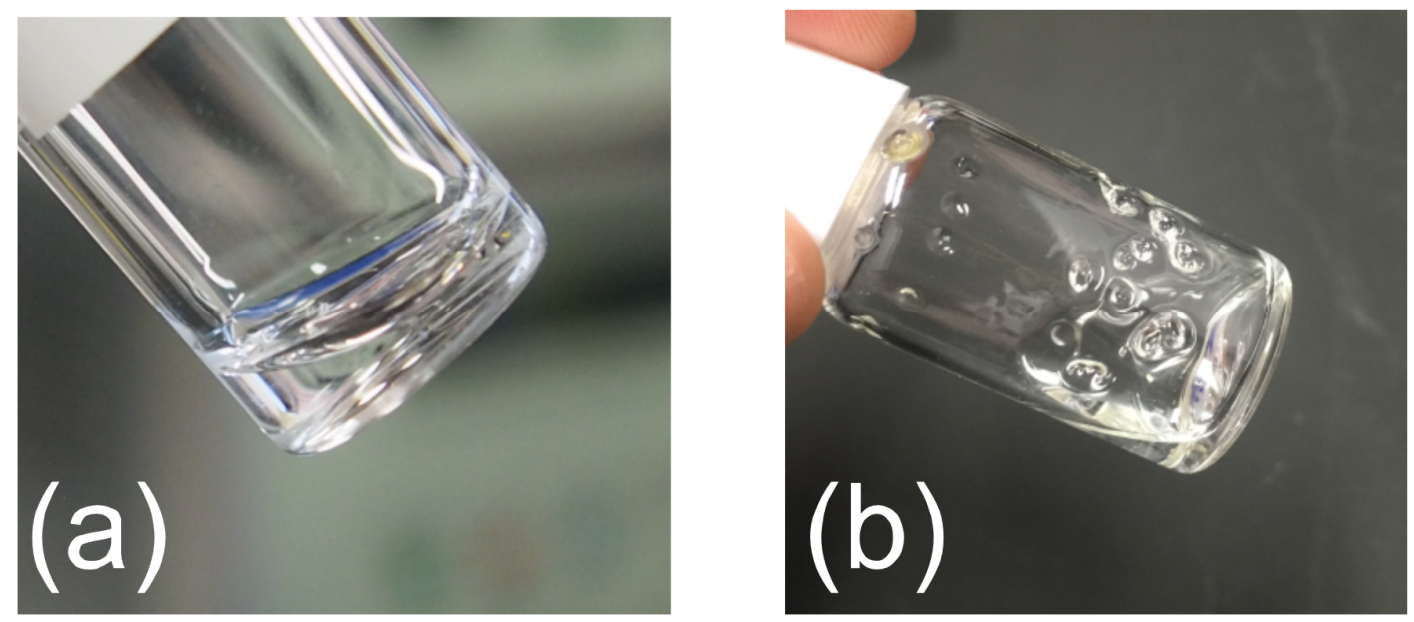

Fig. 3. Photographs of (a) PVAc/[Li(G4)][TFSA] and (b) PVA-66/[Li(G4)][TFSA]. Polymers were mixed with [Li(G4)][TFSA] electrolyte and stirred for $24 \mathrm{~h}$ at $80^{\circ} \mathrm{C}$. 

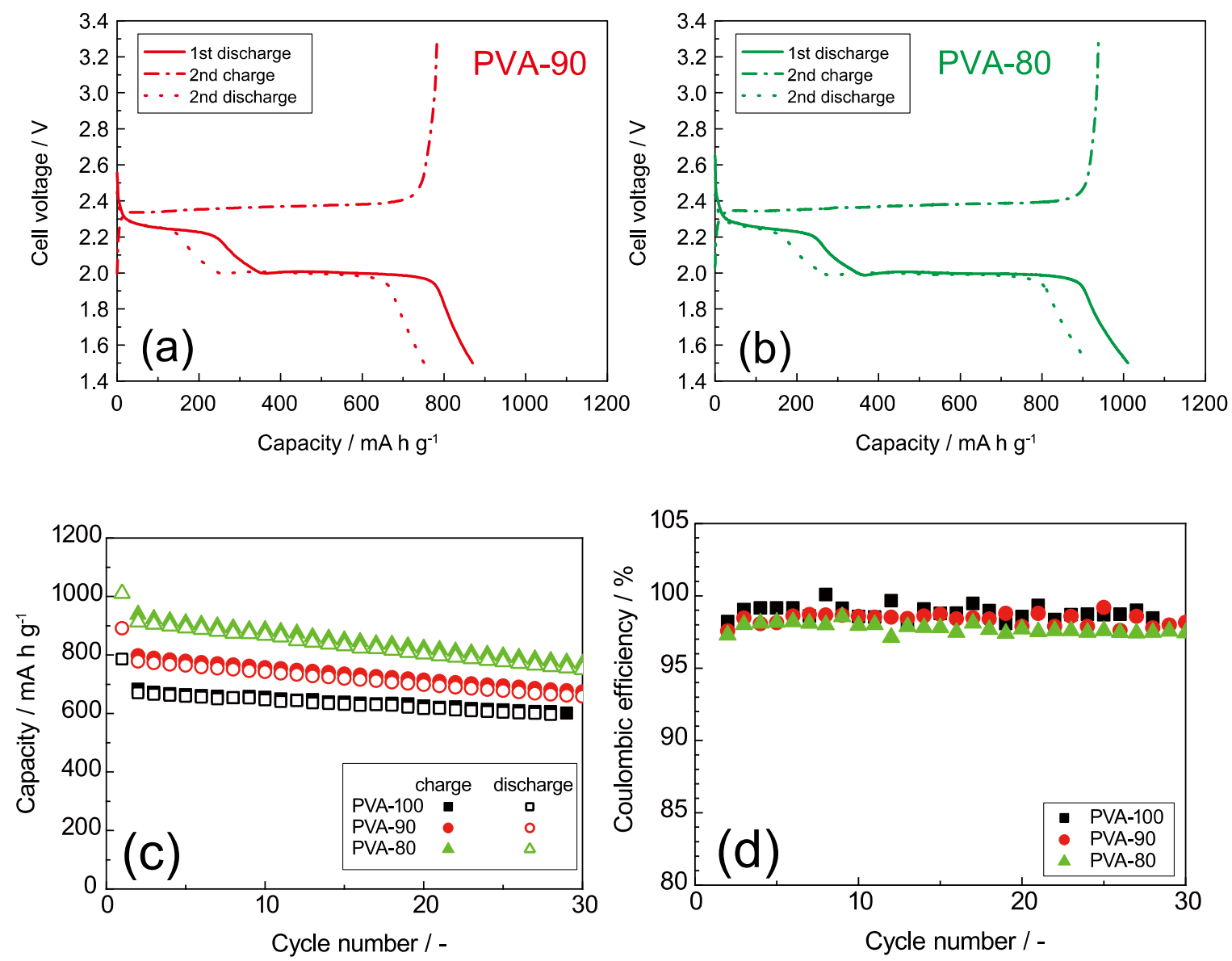

Fig. 4. Discharge and charge and curves of Li-S cells with (a) PVA-90 binder and (b) PVA-80 binder. Dependences of (c) discharge-charge capacities and (d) coulombic efficiency on cycle number. Charge and discharge measurements were carried out at a current density of $139 \mathrm{~mA} \mathrm{~g}^{-1}$ at $30^{\circ} \mathrm{C}$. 


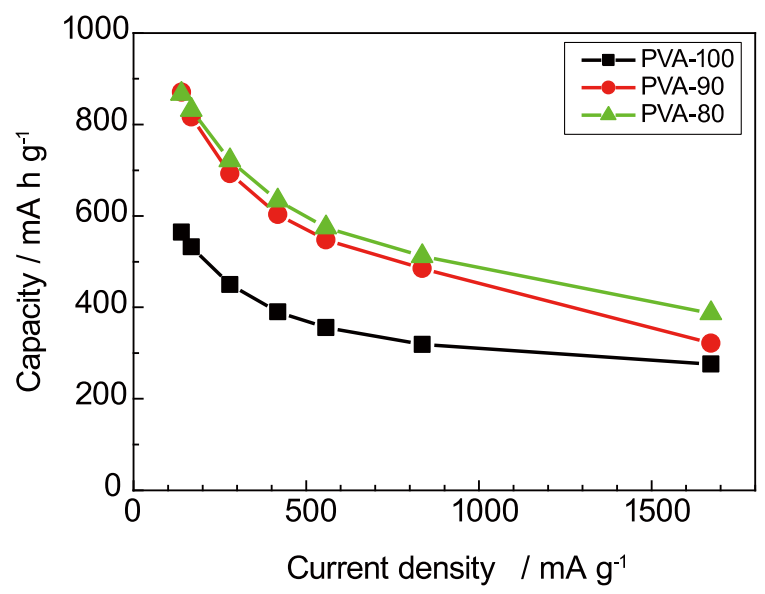

Fig. 5. Dependence of discharge capacity of Li-S cells on current density at $30^{\circ} \mathrm{C}$. The cells were charged up to $3.3 \mathrm{~V}$ at a current density of $139 \mathrm{~mA} \mathrm{~g}^{-1}$ prior to each discharge test. 